\title{
Rigid-flex Hybrid Model Foundation and Statics Simulation Analysis for the NGW31 Planetary Gear Reducer Based on Romax Designer
}

\author{
Chunming $\mathrm{Xu}^{1, \mathrm{a}^{*}}$, Ze Liu ${ }^{1, \mathrm{~b}}$, Yang He${ }^{1, \mathrm{c}}$ and Wenjun Chang ${ }^{1, \mathrm{~d}}$ \\ ${ }^{1}$ College of Machinery and Automation, Wuhan University of Science and Technology, \\ 430081 Wuhan, China

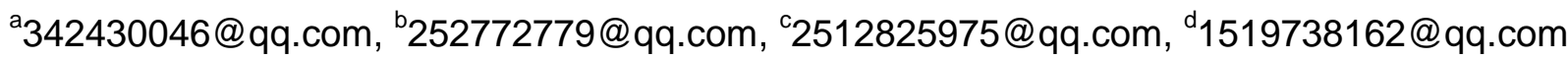

Keywords: Planet gear transmission; Romax Designer; Statics; Contact stress; Simulation analysis.

\begin{abstract}
With the NGW31 planetary gear reducer as the research object, combined with the related parameters of the planetary gear reducer, the traditional rigid model of the transmission system was established based on the conceptual model. And the traditional rigid model is taken as the basis, rigid-flex hybrid model of transmission system was established for a NGW31 planetary gear reducer based on the Roamx Designer. At the same time, the statics analysis was taken for the gear of planetary gear reducer under the two models of traditional rigid model and rigid-flex hybrid model. The results of analysis show that maximum contact stress of the gear under the rigid-flex hybrid model is significantly greater than the traditional rigid model, it is more close to the real conditions, which indicated that the rigid-flex hybrid model is more reasonable and reliable than the traditional rigid model.
\end{abstract}

\section{Introduction}

Transmission device is an important part of the machine, the performance of the machine is largely affected by the performance of the transmission device. Therefore, it has a great significance to making in-depth research on the design, manufacture and optimization of the driving device. In the machinery transmission, the gear transmission is the most common transmission form, the main features is high efficiency, compact structure, high reliability, long service life, constant transmission ratio. The system formed by a series of gear transmission is called gear train. According to the spatial position of each gear axis is changed or not when it is running, the gear train can be divided into epicyclical gear train and ordinary gear train. Epicyclical gear train which has only one plane mechanic freedom went by the name of planet wheel system, and it owned some advantage like small size, light weight, high carrying capacity, high transmission power, large transmission ratio; high transmission efficiency and high reliability [1-2]. It is precisely because of the advantages and characteristics of planetary gear transmission, so that it is widely used in various industrial fields. In the rapid development process of modern industry, the renewal speed of the gear reducer is accelerating and the function structure is more and more complex, so the design of reducer is becoming more and more important in the cycle of its renewal. In order to improve the design level and efficiency of the reducer, make the design fit the objective reality better, further shorten design cycle and depress the design cost, the virtual prototyping technology was introduced into the design work [3-4]. In this context, this paper based on the Romax Designer, a mechanical system virtual prototyping simulation software for gear transmission, makes a modeling and static analysis of NGW31 planetary gear reducer [5].

\section{Establishment of Rigid-flex Hybrid Model}

There are several steps can be used to build the NGW31 planetary gear reducer modeling based on the Romax Designer [6-8]. Firstly, to establish the conceptual model, which includes the built and assemble of 3D model of the basic parts, such as shaft, bearing, planetary gear system, planet carrier and so on and the test of the model; secondly, to establish the rigid model: based on the last step, the 
conceptual model of planetary gear can be transformed into a detailed gear model by setting the detailed design parameters of the gears; thirdly, to establish the rigid-flex hybrid model, by introducing the flexible body finite element model and fitting them together, the whole rigid-flex hybrid model was obtained.

Structure and Parameters of NGW31 Planetary Gear Reducer. The NGW31 planetary gear reducer which is studied in this paper is composed of the single stage planetary gear transmission, and its transmission structure diagram as shown in Fig. 1, among them the ring gear is fixed and sun gear rotates as input, so the ring gear will rotate as output. Its input torque is $360 \mathrm{~N} \cdot \mathrm{m}$ and input speed is 640r/min. The design parameters of the gears as shown in Table 1.

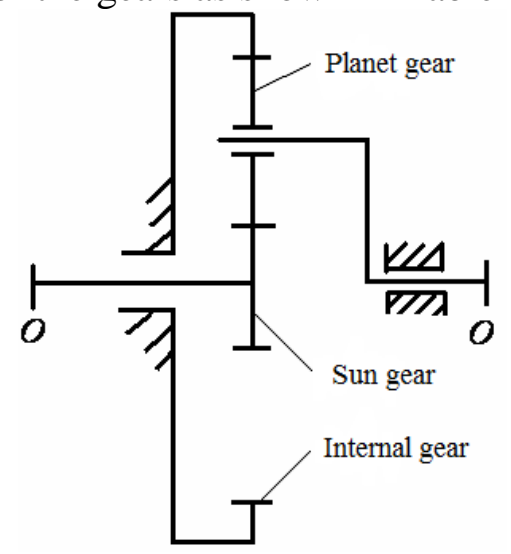

Figure 1. NGW31 planetary gear reducer transmission structure diagram

Table 1 Design parameters of gear

\begin{tabular}{|c|c|c|c|c|}
\hline Driving medium & Number of teeth & $\begin{array}{c}\text { Modulus }[\mathrm{mm} \\
]\end{array}$ & Pressure angle & Gear width $[\mathrm{mm}]$ \\
\hline Sun gear & 20 & \multirow{3}{*}{2.5} & \multirow{3}{*}{20} & 30 \\
\hline Planet gear & 34 & & & 34 \\
\hline Internal gear & 88 & & & 30 \\
\hline
\end{tabular}

Establishment of Transmission System Conceptual Model. According to the design parameters of the gears, including the module, the pressure angle, the number of planetary gear wheel, the number of gear teeth and tooth width, the definition of the planet gear can be completed by Concept Planetary, a component of Romax Designer, and then the Module and number of teeth which can be found in design tool for planetary gear would be selected as the input mode. The conceptual model of planetary gear as shown in Fig. 2.

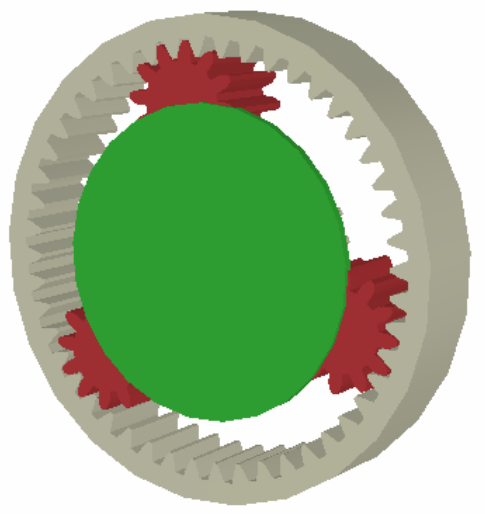

Figure 2. Conceptual model of planetary 
Establishment of Transmission System Rigid Model. After the concept model of transmission system is established. Due to the concept of gear only can be used for transmission, it can't be used to provide sufficient parameters for check calculation of gear strength. In order to check the strength of planetary gear, the concept of the gear model is translated into a detailed planetary gear. A detailed model of planetary gear that has been translated is shown in Fig. 3[9] On the basis of this, the rigid model of transmission system can be established. The rigid model of the transmission system as shown in Fig. 4 [10].

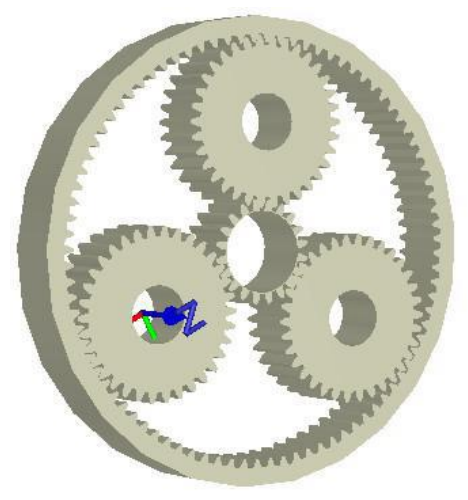

Figure 3. Detail model of planetary

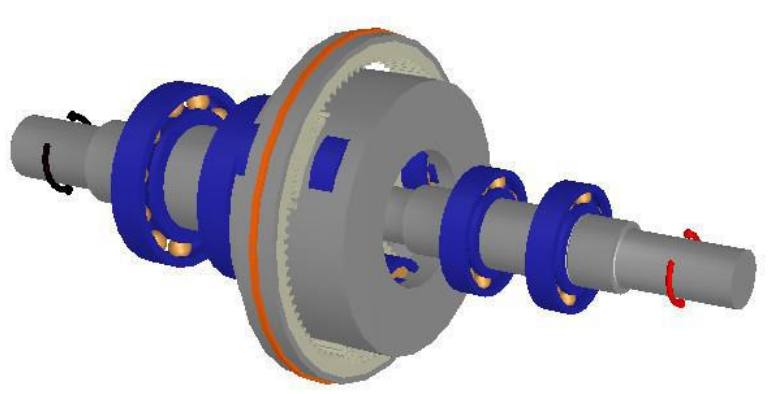

Figure 4. Rigid model of transmission system

Establishment of Transmission System Rigid Flexible Model. In the NGW31 planetary gear reducer, two parts of the planet carrier and the box can be regarded as flexible body and can be carried out the introduction and the assembly of the finite element model, so tht establish the model of rigid mixed with flexible and multi-body dynamics. The example is taken by the planet carrier of planetary gear reducer and the process of flexible body modeling is that the 3D solid model of the planet carrier is established firstly, and then the finite element model is built up based on it. Finally, the 3D model of the flexible body is obtained by Romax Designer. The 3D solid model, the finite element model and the flexible 3D model of the planet carrier as shown in Fig. 5.
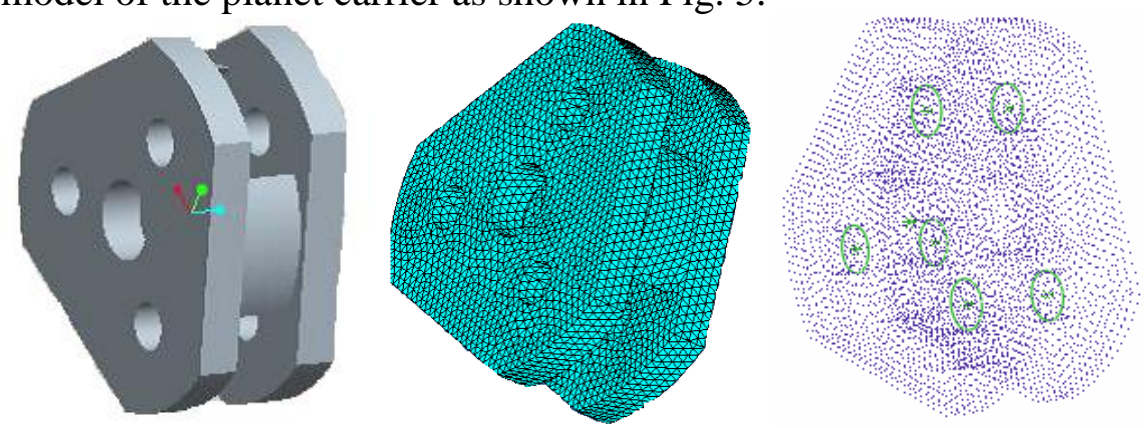

Figure 5. 3D model, finite element model and flexible body model of the planet carrier

With the same modeling process, the box of the reducer is modeled for flexible body, and then it is introduced into the rigid model of the transmission system with the flexible body model of the planet 
carrier. It can be that the whole reducer system of rigid flexible mixed model is got. System for NGW31 planetary gear reducer of rigid flexible mixed model is shown in Fig. 6.

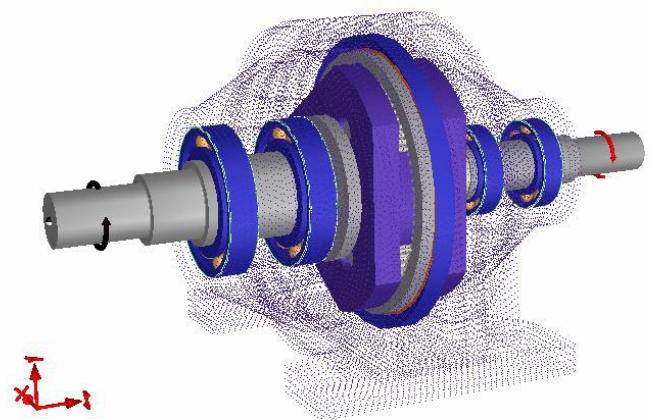

Figure 6. Rigid flexible hybrid model of NGW31 planetary gear reducer

\section{Static Simulation Analysis of Transmission System}

After the traditional rigid model and rigid-flex hybrid model of transmission system for the NGW31 planetary gear reducer have been established, the static simulation analysis is carried out on the gear of the planetary gear reducer. The maximum contact stress of gear is simulated and analyzed. The simulation results of the traditional rigid model are shown in Fig. 7, the rigid flexible mixed model are shown in Fig. 8.

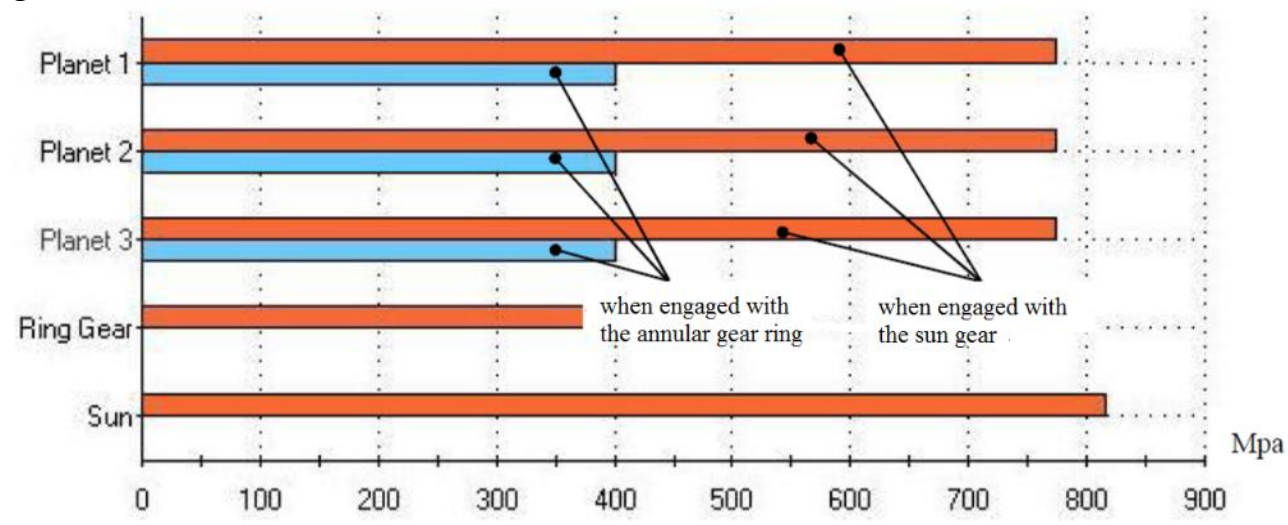

Figure 7. Maximum contact stress of gear under the traditional rigid model

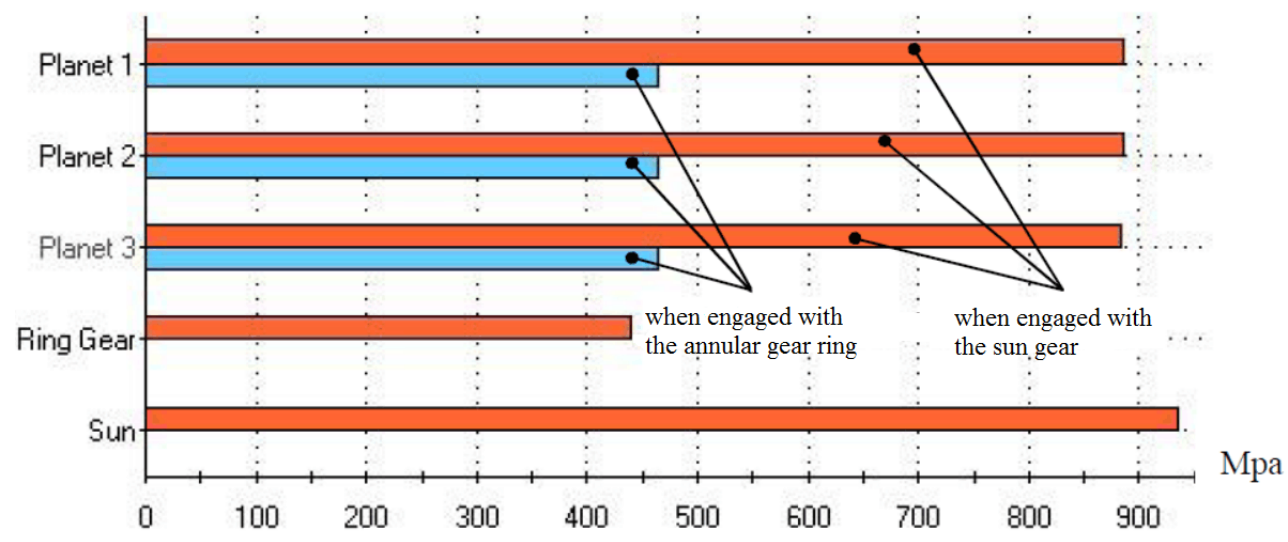

Figure 8. Maximum contact stress of gear under the rigid flexible mixed model

Fig. 7 and Fig. 8 shows the maximum contact stress of each gear under different models. The Planet1, Planet 2 and Planet 3 are the maximum contact stress between the three planetary gears and the inner gear ring and the sun wheel respectively. The Gear Ring bar chart indicates the maximum 
contact stress between the inner gear ring and the three planet gears. Sun bar chart indicates the maximum contact stress between the sun wheel and the three planet wheels.

It can be seen from Fig. 7 and Fig. 8 that the maximum contact stress of the rigid flexible gear model is significantly greater than the traditional rigid model under the stress of gear, the reason is that the rigid flexible hybrid model take the flexible structure fully into consideration, the gear contact stress simulation result is more close to the real condition. This shows that the rigid flexible hybrid model is more reasonable and reliable than the traditional rigid model.

\section{Conclusion}

With the NGW31 planetary gear reducer as the research object, the traditional rigid model of the transmission system was established on the basis of the concept model and the detailed model of the gear reducer. The flexible body 3D model of the planetary frame and the box body of planetary gear are built by Romax Designer, and imported it to the traditional rigid model, after that established the rigid-flex hybrid model of the transmission system. After the traditional rigid model and the rigid-flex hybrid model are built, maximum contact stress of the gear under two models was analyzed. The results of analysis show that maximum contact stress of the gear under the rigid-flex hybrid model is significantly greater than the traditional rigid model, it is more close to the real conditions, which indicated that the rigid-flex hybrid model is more reasonable and reliable than the traditional rigid model.

\section{References}

[1] Z.R Zhu, L.D Jiang and S Chang; Latest advances in involute planetary gear transmission technology. Journal of Engineering for Thermal Energy and Power, Vol. 22(2007) No.4, p.352-356.

[2] R Yuan, S.M Wang and Y.W Shen; Study on dynamic efficiency of high-speed planetary transmission. Mechanical Science and Technology for Aerospace Engineering, (2001) No.5, p.670-671,631.

[3] X Zu, H.Z Huang and X Zhang; Virtual prototyping and its development. Transactions of the Chinese Society for Agricultural Machinery, Vol. 35(2004) No.2, p.168-170.

[4] Y.X Yang, D.J Guo; Application of virtual prototype technique to the design of a transmission. Construction Machinery and Equipment, Vol. 41(2010) No.8, p.52-56.

[5] X.L Zhu, H.G Xiong; Finite element modal analysis of reducer box based on Romax. Journal of Mechanical Transmission, Vol. 37(2013) No.2, p.94-96.

[6] J.J. Yang, W. Liu and H. Zhang, et al: Research of the optimization design and experimental of gear modification based on ROMAX. Journal of Mechanical Transmission, Vol. 39(2015) No.10, p.158-161.

[7] F.Z. Sun: Analysis on gear modification of a tractor transmission based on Romax software. Journal of Shandong Agricultural University (Natural Science Edition), Vol. 45(2014) No.5, p.702-705

[8] X.L Zhu, H.G Xiong; Finite element modal analysis of reducer box based on Romax. Journal of Mechanical Transmission, Vol. 37(2013) No.2, p.94-96.

[9] J.H. Lu, B. Li, R.P. Zhu: Analysis of static load sharing in planetary gearing. Mechanical Science and Technology, Vol. 24(2005) No.6, p.702-704, 709. 
[10]F.M Ye, J Gao and W Jiang; Unequal assembly method and Pro/E modeling simulation of NGW planetary gear train. Journal of Jiangsu University of Science and Technology, Vol. 26(2012) No.6, p.254-257. 